\title{
Investigation of Solid Precipitate that Prevents Etching of Silicon in a Solution of Ethylenediamine and Pyrocatechol
}

\section{S. Veselov, Y. A. Voronov, and Y. R. Shaltaeva}

National Research Nuclear University MEPhI (Moscow Engineering Physics Institute), Kashirskoe shosse 31, Moscow, 115409, Russia

\section{Abstract}

The article studies effect of solid precipitate building up that prevents etching of silicon in a solution of ethylenediamine and pyrocatechol. The article provides technology recommendations that allow avoiding the formation of the undesirable solid precipitate.

Corresponding Author:

D. S. Veselov

DSVeselov@mephi.ru

Received: 22 July 2018

Accepted: 9 September 2018

Published: 8 October 2018

Publishing services provided by Knowledge E

(c) D. S. Veselov et al. This article is distributed under the terms of the Creative Commons

Attribution License, which permits unrestricted use and redistribution provided that the original author and source are credited.

Selection and Peer-review under the responsibility of the Breakthrough Directions of Scientific Research at MEPhI Conference Committee.

\section{Introduction}

Nowadays a large number of different solutions are known for the anisotropic etching of silicon: aqueous solutions of potassium hydroxide $(\mathrm{KOH})$, an aqueous solution of tetramethylammonium hydroxide $\left(\mathrm{C}_{4} \mathrm{H}_{13} \mathrm{ON}\right)$, aqueous solutions based on ethylene diamine $\left(\mathrm{C}_{2} \mathrm{H}_{8} \mathrm{~N}_{2}\right)$ and pyrocatechol $\left(\mathrm{C}_{6} \mathrm{H}_{6} \mathrm{O}\right)$, and solutions based on hydrazine hydrate $\left(\mathrm{N}_{2} \mathrm{H}_{4}\right)$ [1-25].

The aqueous solution based on ethylene diamine $\left(\mathrm{C}_{2} \mathrm{H}_{8} \mathrm{~N}_{2}\right)$ and pyrocatechol $\left(\mathrm{C}_{6} \mathrm{H}_{6} \mathrm{O}_{2}\right)$ are applicable for microelectromechanical structures technology (MEMS) due to a large ratio of etching rates of silicon and silicon thermal oxide masking, which allows obtaining a deep cavity in the silicon substrate. The treatment of silicon in such solutions is complicated by the formation of a solid precipitate that locally prevents access of etchant to etching surface. Mentioned effect leads to a very irregular profile of the treated surface.

For the studies were used ethylene diamine and pyrocatechol from Merck (Germany) characterized by purity class 'for synthesis', which corresponds to the cleanliness class in the RF standards. During that was studied the etching rate of silicon in the (100) crystal plane.

Based on the results of preliminary studies, it was found that the simple dissolution of pyrocatechol in ethylene diamine does not allow to obtain solutions of the required 
composition for carrying out the process of anisotropic etching of silicon. Oxidation of solutions was used by bubbling with oxygen during the preparation of the etchant at various range of temperature from 25 to $100^{\circ} \mathrm{C}$ with adding water for activation of solutions etching properties. The bubbling process of oxidation an etchant solution does not effective for solutions with small concentrations of pyrocatechol over the entire temperature range [209]. In the process of etching, both in oxidized and introductory solutions on many samples, a solid white precipitate is formed. That precipitate is locally blocking the etching (Figure 1).

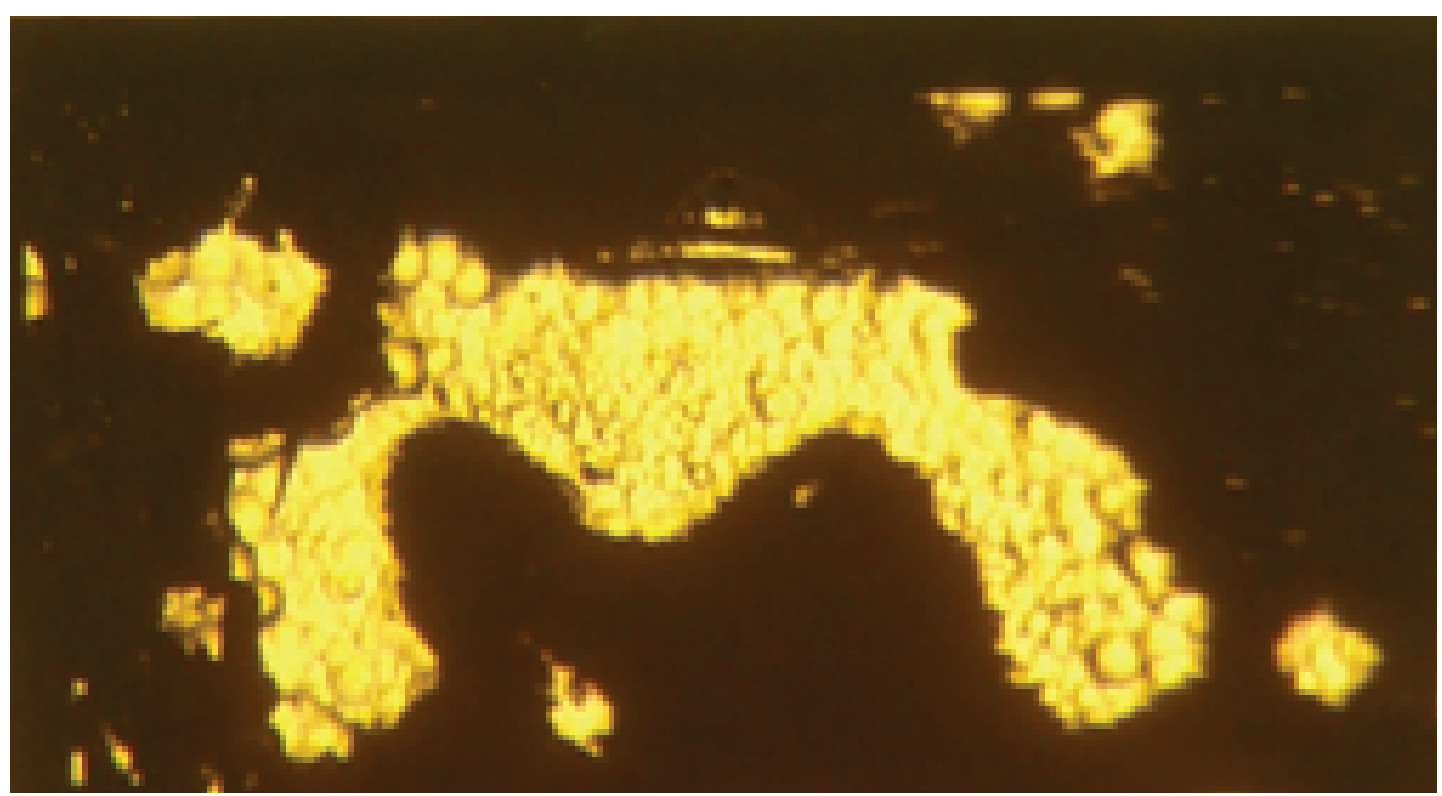

Figure 1: The microscopic photo of etching area with a layer of precipitate locally blocking the etching.

\section{Materials and Methods}

To exclude the formation of solid precipitate, various articles propose various concentrations of following solution compositions:

1. Ethylene diamine : Pyrocatechol : Water (E:P:W)

2. $E: P: W=7.5 \mathrm{ml}: 1.2 \mathrm{~g}: 2.4 \mathrm{ml}[186]$;

3. $E: P: W=7.5 \mathrm{ml}: 2.4 \mathrm{~g}: 2.4 \mathrm{ml}[186]$;

4. $E: P: W=17 \mathrm{ml}: 3 \mathrm{~g}: 8 \mathrm{ml}[196]$;

5. $\mathrm{E}: \mathrm{P}: \mathrm{W}=225 \mathrm{ml}: 45 \mathrm{~g}: 120 \mathrm{ml}[182]$

6. $\mathrm{E}: \mathrm{P}: \mathrm{W}=750 \mathrm{ml}: 120 \mathrm{~g}: 100 \mathrm{ml}[184]$. 
In the case of the developed technology, the selection of a solution composition only by the criterion of formation of a precipitate is not suitable, since it is necessary to study a wide range of concentrations of the components to be able to find controlling criteria of solution suitability and to choose the preferred one.

It is chosen based on compound of solution for the studies: ethylene diamine. The concentration of basis compound varies depending on the changes in the concentrations in the solution of both pyrocatechol and water, which are varied in the range of $10-35 \%$ of the total mass of the solution.

The two stages of research were carried out to determine the best method of preparation and the range of optimum concentrations of the solution components. At the first stage, solutions prepared on the basis of different oxidation times at room temperature, solutions based on ethylene diamine were investigated with a concentration of pyrocatechol in the range $15-35 \%$ of the total mass of the solution. The dielectric films $2 \mu \mathrm{m}$ thick were deposited on the samples To determine the etching resistance of dielectric membrane films obtained by reactive magnetron sputtering. A metal wiring was formed on the dielectric films, covered with a layer of dielectric insulating made of the same material with a thickness of about $300 \mathrm{~nm}$. The visual evidence of the etchant effect on the film was the peeling of the elements of the metallic wiring. The confirmation of etching in the test solution was a change in the thickness, measured by the preparation of profilograms of etched regions of the film 2-4 mm wide. The etching time of dielectric films varied from 3 to 5 hours.

\section{Results}

In the course of the study, it was found that oxidation of this type of organic solution makes it possible to activate its etchability to silicon, but the etching process is characterized by an unstable etching rate. It was also found that all the obtained solutions have a strictly limited period of conservation of the etching properties. At high and very low pyrocatechol concentrations, the etching surface is highly uneven. It was also found that when the solution is infiltrated after oxidation, the etching rates increase, and the period of preservation of the ability of the solution to etch decreases. It was found that magnetron sputtered silicon oxide films have a resistance to etching in an oxidized solution of ethylene diamine : pyrocatechol $=75 \%: 25 \%$ by weight, but only with prolonged oxidation. This etchant solution do not have acceptable for the developed technology uniformity of etching and is characterized by poor reproducibility of the results. 


\section{Discussion}

The obtained modes and solutions are suitable for use in the manufacture of dielectric membrane structures. It is optimal to use a combination of etching at $100^{\circ} \mathrm{C}$ in a solution of $\mathrm{E}: \mathrm{P}: \mathrm{B}=55 \%: 20 \%: 25 \%$ after infusion for two days for carrying out the main stage of anisotropic silicon etching. For the final stage of anisotropic silicon etching, the process in optimal solution is: $\mathrm{E}: \mathrm{P}: \mathrm{B}=55 \%: 20 \%: 25 \%$ at $80^{\circ} \mathrm{C}$.

\section{Conclusion}

The investigation of various modes of anisotropic etching of silicon in ethylenediamine solutions with the addition of pyrocatechol. It was determined the etching rates of silicon and thermal silicon oxide and the periods of preservation of the etching properties of the solutions that allows to carry out the uniformity of etching. The obtained solutions make it possible to achieve a uniformity of etching of silicon at a level of 1-2 $\mu \mathrm{m}$ with a depth of etching more than $150 \mu \mathrm{m}$. Obtained technology allows etching without forming V-shaped grooves along the perimeter of the etching cavities and prevents forming of a solid precipitate locally blocking the etching process and, as a consequence, to improve the quality and yield of manufactured MEMS.

\section{References}

[1] Kumar, S. and Gerhardt, R. A. (2012). Role of geometric parameters in electrical measurements of insulating thin films deposited on a conductive substrate. Measurement Science and Technology, vol. 23, no. 3.

[2] Holwill, R. J. (1989). Materials Science and Engineering: A, vol. 116, pp. 143-145.

[3] Toyoda, S., Kiyota, T., Tamagawa, K., et al. Materials Science and Engineering: A, vol. 163, no. 2, pp. 167-170.

[4] Kawabata, K., Tanaka, T., and Kajioka, H. (1993). Materials Science and Engineering: A, vol. 163 , no. 2 , pp. $163-165$.

[5] Fujimura, N., Nishida, N., Ito, T., et al. (1989). Materials Science and Engineering: $A$, vol. 108, pp. 153-157.

[6] Jeyachandran, Y. L., Karunagaran, B., Narayandass, Sa. K., et al. (2006). Materials Science and Engineering: $A$, vol. 431, nos. 1-2, pp. 277-284.

[7] Chopra, K. L. (1972). Electrical Phenomena in Thin Films, p. 435. Moscow: Russia. 
[8] Xian-ping, Wu, Oing-hai, Wu, Ko Wen, H. (1985). Исследование процесса глубинного травления кремния в травителе ЭДА +ПК $+\mathrm{H}_{2} \mathrm{O}$ [Transducers-85. International Conference on Solid-State Sensors and Actuators]. Digest of Technical Papers pp. 291-294. New York, NY.

[9] Jolly, R. D. and Muller, R. S. (1980). Miniature cantilever beams fabricated by anisotropic etching of silicon. Journal of the Electrochemical Society, vol. 127, pp. 27502754 .

[10] Smith, R. L., Clock, B., De Rooij, N., et al. (1987). The potential dependence of silicon anisotropic etching in $\mathrm{KOH}$ at $600 \mathrm{C}$. Journal of Electroanalytical Chemistry, vol. 238, pp. 103-113.

[11] Schroder, H. and Obermeier, E. (2000). A new model for Si (100) convex corner undercutting in anisotropic $\mathrm{KOH}$ etching. Journal of Micromechanics and Microengineering, vol. 10, no. 2, pp. 163-170.

[12] Schroder, H., Obermeier, E., and Steckenborn, A. (2001). Micropyramidal hillocks on $\mathrm{KOH}$ etched (100) silicon surfaces: Formation, prevention and removal. Journal of Micromechanics and Microengineering, vol. 9, no. 2, pp. 139-145.

[13] Conway, E. M. and Cunnane, V. J. (2001). Effects of chemical pretreatments on the etching process of $p(100) \mathrm{Si}$ in tetra-methyl ammonium hydroxide. Journal of Micromechanics and Microengineering, vol. 11, no. 3, pp. 245-256.

[14] Powell, O. and Harrison, H. B. (2002). Anisotropic etching of (100) and (110) planes in (100) silicon. Journal of Micromechanics and Microengineering, vol. 11, no. 3, pp. 217-220.

[15] Thong, J. T., Luo, P., and Tan, S. C. (2001). Evolution of hillocks during etching in TMAN. Journal of Micromechanics and Microengineering, vol. 11, no. 1, pp. 61-69.

[16] Abu-Zeid, M. M. (1984). Corner undercutting in anisotropically etched isolation contours. Journal of the Electrochemical Society, vol. 131, no. 9, pp. 2138-2142.

[17] Veselov, D. S. and Voronov, Yu. A. (2016). Formation of dielectric silicon compounds by reactive magnetron sputtering. Journal of Physics: Conference Series, p. 747, 012022.

[18] Veselov, D. S., Bakun, A. D., and Voronov, Yu. A. (2016). Analytical model of plasmachemical etching in planar reactor. Journal of Physics: Conference Series, p. 748, 012017. 